\title{
卜
}

Die Swell of Low Density Polyethylene through Converging Slit Die

by

Shinichi SuTo

Department of Polymer Chemistry, Faculty of Engineering,

Yamagata University, Yonezawa, Yamagata 992

In order to discuss effects of branching and shear history on die swell, die swell has been determined for a series of low density polyethylenes characterized in terms of their molecular weights and branching indexes. Several slit dies with different gaps are arranged in series in order to form stepwise converging channels.

Die swell increased with branching. Die swell through the stepwise converging slit die depended almost solely on the final die, and effect of shear history on elasticity was not observed. Die swell of low density polyethylene was governed by Weissenberg number (ratio of principal normal stress difference to shear stress at the wall).

\section{縮小型スリットダイにおける低密度ポリエチレンの ダイスウェル}

\author{
須藤 新 一* \\ （原稿受理：1981年11月13日）
}

\section{1. 緒言}

工学的にも工業的にもダイスウェル現象への関心は高い.円管 拉よびスリットに括けるダイスウェルの理論解析も, ニュートン 流(体 ${ }^{1), 2)}$, 非ニュートン流体 ${ }^{3) \sim 6)}$ ともにすでになされている. し かし, 実際の成形加工ではダイ形状が縮小型や桩大型など単純で ない場合も多い，そこで，ダイスウェルに対するダイ形状の影響 に関する知見が必要となる。

$\mathrm{Han}^{7)}$ や $\mathrm{Banker}^{8}$ ら 圧やダイスウェルへの影響を，また Chee ら ${ }^{9}$ は縮小型执よび拡 大型ダイについてダイスウェルへのせん断履歴の影響を報告して いる. 筆者ら ${ }^{10), 11)}$ も高密度ポリエチレンを用いて縮小型扣よび 拡大型スリットダイについて，エネルギー収支をもとにダイスウ ェルを予測し，実測值とのよい一致をみた。また，縮小型ダイの 場合, ダイスウェルへのせん断履歴の影響は少ないという結果を 報告した。

\footnotetext{
*山形大学工学部高分子化学科 $\overline{7} 992$ 米沢市城南 4 丁目 $3-16$
}

しかし，低密度ポリェチレンの異形ダイダイスウェルについて 研究は少ない。これは低密度ポリエチレンの場合, 分岐の影響が 考劣られ, 現象が複雑なためと考学られる. 高分子粘弾性への分 岐の影響について，多くの報告はあるが，そのほとんどは粘度に 関するもので12) 17), ダイスウェルについては少ない(18) 20). 特に せん断履歴の影響については活とんどない20).

そこで本報では市販低密度ポリエチレンについて, 縮小型ダイ を用い, ダイスウェルへの分子構造掞よびせん断履歴の影響を考 察する. そのため, 寸法の異なるスリットダイを重ねてダイスウ ェルを測定した.

$$
\text { 2. 方法 }
$$

\section{$2 \cdot 1$ 試 料}

用いた試料は市肘低密度ポリエチレン 4 種類で，そのメルトイ ンデックス, 密度およびゼロせん断粘度を Table I に示した. $g \bar{M}_{w}$ は Mendelson ら ${ }^{13)}$ の次式により求めた。

$\log \eta_{0}=-30.19+\left(2.55 \times 10^{3} / T\right)+6.56 \log \left(g \vec{M}_{w}\right)$ 
Table I. Characteristics of Low Density Polyethylenes.

\begin{tabular}{cccccc}
\hline Sample & MI & Density & $\begin{array}{c}\eta_{0} \\
(\mathrm{~Pa} \cdot \mathrm{s})\end{array}$ & $\begin{array}{l}g \cdot{ }_{w} \bar{M}^{\mathrm{a})} \\
\times 10^{-4}\end{array}$ & $\begin{array}{c}g \cdot \tau^{\mathrm{b})} \\
(\mathrm{sec} .)\end{array}$ \\
\hline $\mathrm{A}$ & 0.5 & 0.921 & $4.9 \times 10^{4}$ & 4.16 & $7.67 \times 10^{-1}$ \\
\hline $\mathrm{B}$ & 3.6 & 0.920 & $5.5 \times 10^{3}$ & 2.98 & $6.17 \times 10^{-2}$ \\
\hline $\mathrm{C}$ & 8.9 & 0.917 & $1.6 \times 10^{3}$ & 2.47 & $1.49 \times 10^{-2}$ \\
\hline $\mathrm{D}$ & 19.4 & 0.916 & $7.1 \times 10^{2}$ & 2.18 & $5.86 \times 10^{-3}$ \\
\hline
\end{tabular}

a) Derived from $\eta_{0}$ by using Mendelson's eq. ${ }^{13)}$

b) $\tau$ is Bueche's relaxation time.

ここで， $\bar{M}_{w}$ は重量平均分子量で， $g$ は分岐指数で，同一分子量 を有する分岐高分子扣よび盛鎖高分子の慣性卒径の 2 並平均の比 で定義される ${ }^{21)}$. 分岐が多くなると $g$ は小さくなる，また，ては Bueche の緩和時間である ${ }^{22)}$.

\section{$2 \cdot 2$ 定常せん断粘弾性の測定}

コーン・プレート型ワイセンベルグレオゴニオメーター R-17 型を用い, 低せん断応力領域に扣ける粘度, 扣よび主法線応力差 $N_{1}\left(=\sigma_{11}-\sigma_{22}\right)$ を $184^{\circ} \mathrm{C} て ゙$ 測定した. 結果をFig. 1 に示した. $N_{1}$ はせん断応力に対して，実験範囲内ではほぼ直線関係を示した。

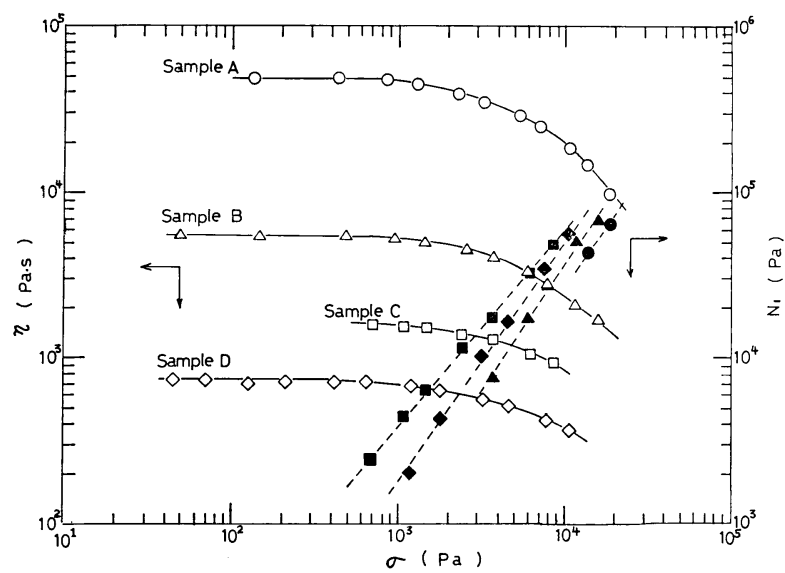

Fig. 1 Plots of steady shear viscosity $\eta$ and principal normal stress difference $N_{1}$ versus shear stress $\sigma$ for low density polyethylene at $184^{\circ} \mathrm{C}$.

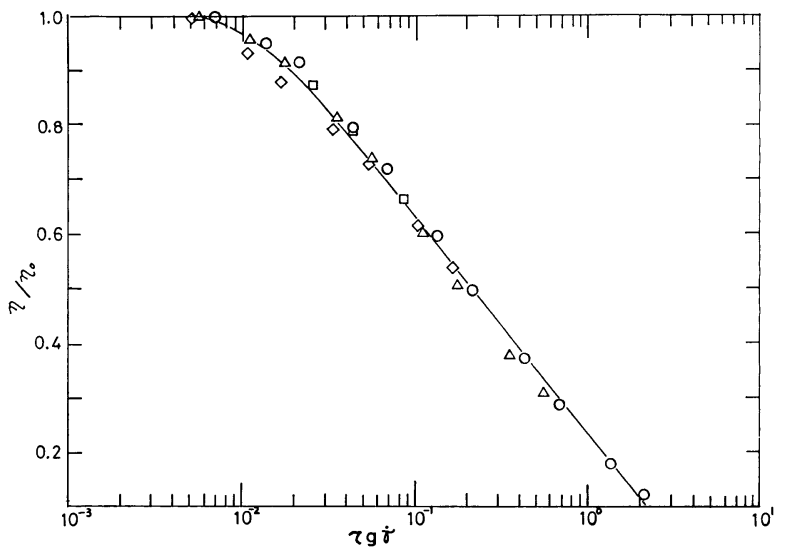

Fig. 2 Plot of $\eta / \eta_{0}$-vs. $\tau \cdot g \cdot \dot{\gamma}$.

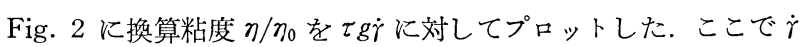
はせん断速度である. 分岐指数 $g$ や緩和時間 $\tau$ を考慮すると，ほ ぼ一本のマスターカーブに重站わせられたことから，各試料の $\tau g$ 执よび $g \bar{M}_{0}$ の精度は高いと思われる．值の正確さについては 本報では検討を加えないこととする.

\section{$2 \cdot 3$ ダイスウェルの測定}

段階的縮小型ダイを Fig. 3 亿示した. スリット幅が同一で, スリット厚の異なる複数個のダイを重齐た．用いたダイの寸法を Table II に示した。試料をリザーバー中で 6 分間予熱後, 定荷重 押出しを行い，そのシート厚を読み取り顕微鏡にて測定した．試 料を約 $1.5 \mathrm{~cm}$ 押し出したところで荷重を除去し，ダイから約 $1.0 \mathrm{~cm}$ 下部のところのシート厚を固化開始前に測定した. Fig. 4 に溶融時のダイスウェルと冷却固化後マイクロメーターで測定し たダイスウェルの比較を示した。 ここで, $\mathrm{W}_{2}+\mathrm{W}_{3}$ は $\mathrm{W}_{2}$ のダ イを $\mathrm{W}_{3}$ のダイの上部に重ねたことを示す。せん断速度は $\dot{\gamma}=$ $(2 n+1 / n)\left(2 Q / W H^{2}\right)$ から求めた。 $n$ はべき法則指数， $W, H$ は それぞれダイの幅, 厚さで，Qは流量である. 縮小型ダイの場合, $H$ H下部ダイの值を用いた. Fig. 4 亿みられるように, 冷却後に 比べ溶融時のダイスウェルは約 $5 \%$ ほど大であった．本報では通 常行う密度補正，アニーリングは省略した。

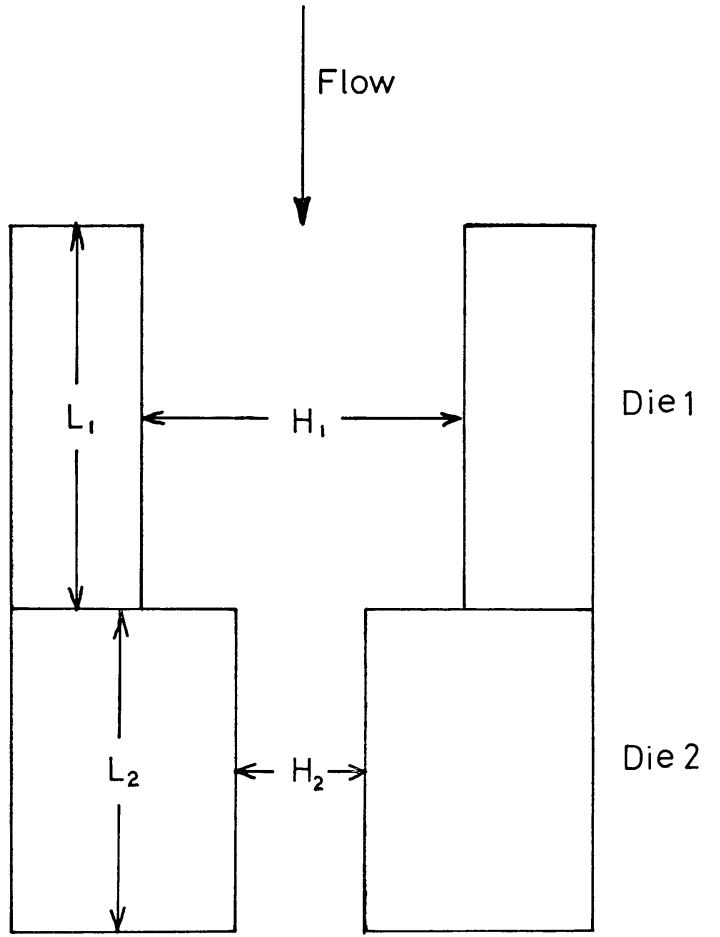

Fig. 3 Schematic diagram of our converging slit die.

Table II. Dimensions of slits.

\begin{tabular}{cccc}
\hline $\begin{array}{c}\text { Die } \\
\text { Designation }\end{array}$ & $\begin{array}{c}\text { Length } L \\
\mathrm{~mm}\end{array}$ & $\begin{array}{c}\text { Width } W \\
\mathrm{~mm}\end{array}$ & $\begin{array}{c}\text { Gap } H \\
\mathrm{~mm}\end{array}$ \\
\hline $\mathrm{W}_{1}$ & 10.0 & 17.3 & 0.92 \\
\hline $\mathrm{W}_{2}$ & 8.00 & 17.3 & 0.62 \\
\hline $\mathrm{W}_{3}$ & 2.05 & 17.3 & 0.33 \\
\hline
\end{tabular}




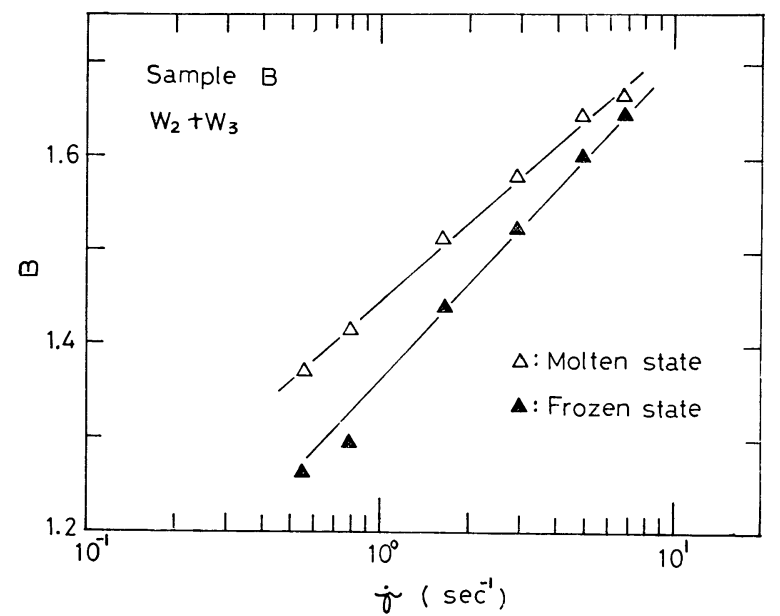

Fig. 4 Comparison of die swell in molten state with die swell in frozen state. In combined die, the upper die is listed first.

\section{3. 結 果}

Fig. 5に単独ダイに怙けるダイスウェルをせん断応力に対しプ ロットした. いずれの試料もせん断応力の増加とともにダイスウ ェルは増大した．同一結果をワイセンベルグ数 $N_{1} / \sigma$ に対してプ ロットし直すと, Fig. 6 亿示したように実験誤差内でほぼ一本の マスターカーブに合成された，実線はWhite らの理論曲線であ $ろ^{6)}$. 実線の場合，実測值に比べ理論值は小さい，そこで同じく White らの方法 ${ }^{6}$ 潐じ， $N_{1}=A \sigma^{a}$ (ここで $A, a$ はともに定数） が成立するとして，Fig. 1亿示した結果をもとに $a$ を求め補正し たのが破線である．高いワイセンベルグ数で理論值と実測值にず れはみられるが，実線の場合に比べよりよい合致をみた。

Fig. 7亿段階的スリットダイに拈けるダイスウェルをせん断速 度に対してプロットした，スリットダイの組み合わせを変えても ダイスウェルはほぼ一本の線上に並り，下部のダイ単独の場合と ほぼ同一の值を示した，他の試料についても同様にほほぼ一本の 線に整理できた。

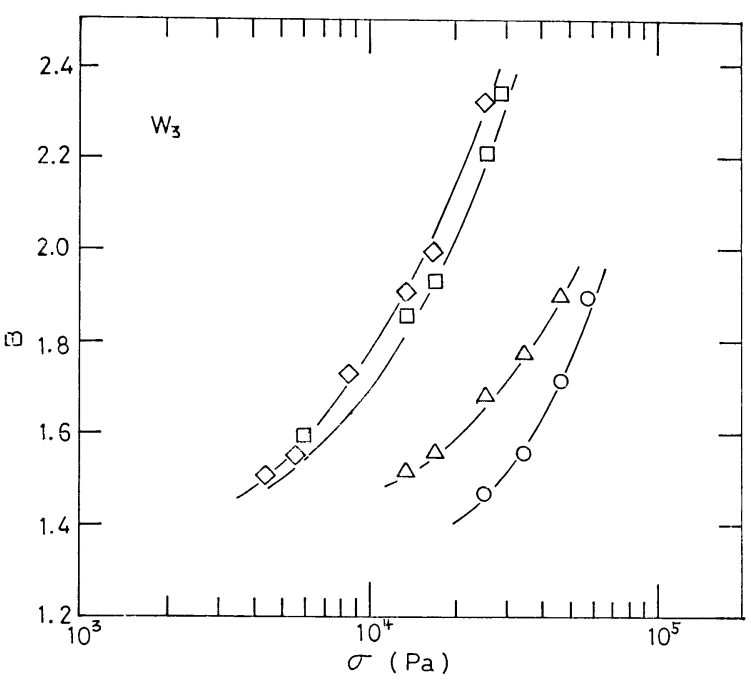

Fig. 5 Die swell through die $\mathrm{W}_{3}$ vs. shear stress at the wall for four low density polyethylenes.

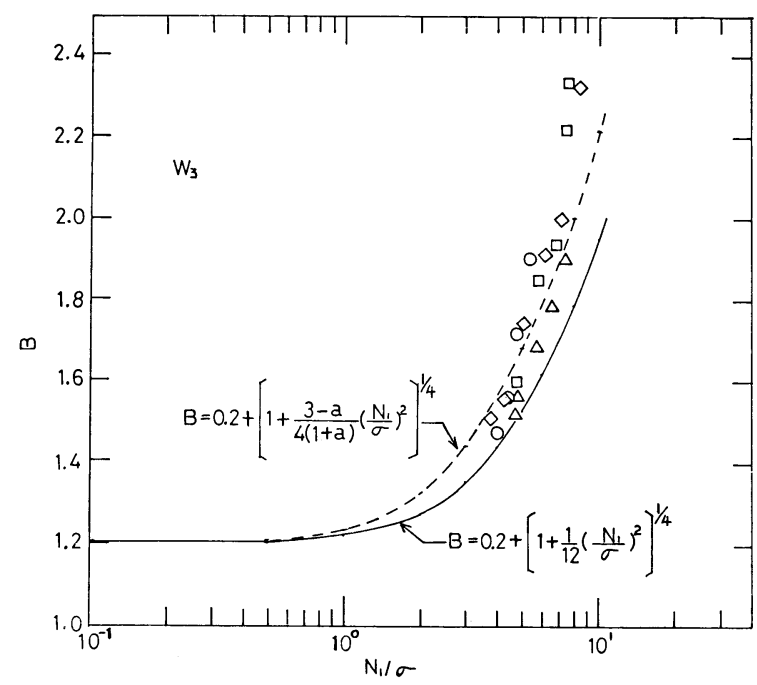

Fig. 6 Die swell plotted against Weissenberg Number (ratio of principal normal stress difference to shear stress at the wall).

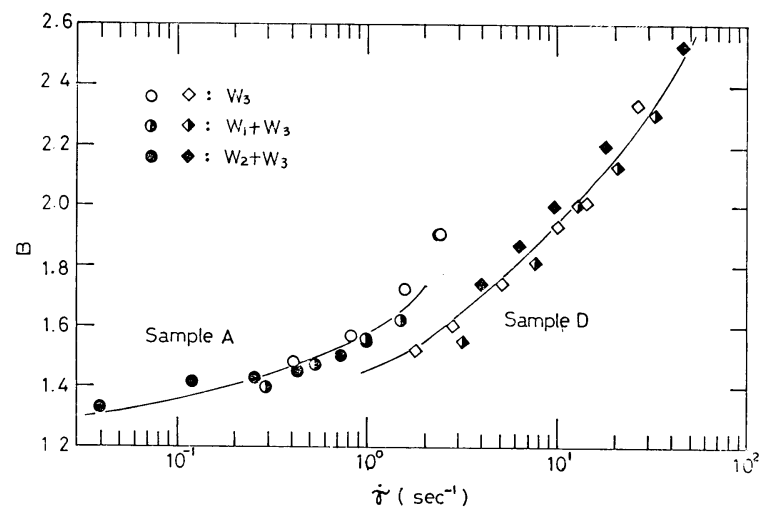

Fig. 7 Die swell plotted against shear rate. In the combined die, the upper die is listed first.

\section{4. 考察}

\section{$4 \cdot 1$ 分子構造の影響}

分岐高分子の弾性挙動については相反する報告がある。すなわ ち，分子量や分子量分布が同一の場合，長鎖分岐の增大とともに 弾性は減少するという Mendelson らの報告13),18) と，增大すると い5 Wild ら ${ }^{19)}$ の報告である。 また，最近六代はせん断履歴の違 いにより長鎖分岐の增大とともにダイスウェルが増大する場合と 減少する場合があると報告しており，それを流動単位のサイズの 変化に原因を求めている20).

本報では長鎖分岐の弾性への影響を検討するため，パラメータ - $g \bar{M}_{w}$ に対してダイスウェルをプロットし Fig. 8 に示した. ダイスウェルは $g \bar{M}_{w}$ の增大とともに減少した。ささ，パラメー ター $g \bar{M}_{w}$ は分岐指数 $g$ と重量平均分子量 $\bar{M}_{w}$ の積の形で示さ れている，そこで，gとダイスウェルの関係を以下で検討する. $\operatorname{Ram}^{23}$ は低密度ポリエチレンのコンプライアンスは長鎖分岐に 影響され，分子量や分子量分布に影響されず，また $g$ の減少とと もにコンプライアンス（ダイスウェル）は増大の傾向を示すこと を報告している．また，六代 ${ }^{20)}$ は逆に分子量や分子量分布が長鎖 


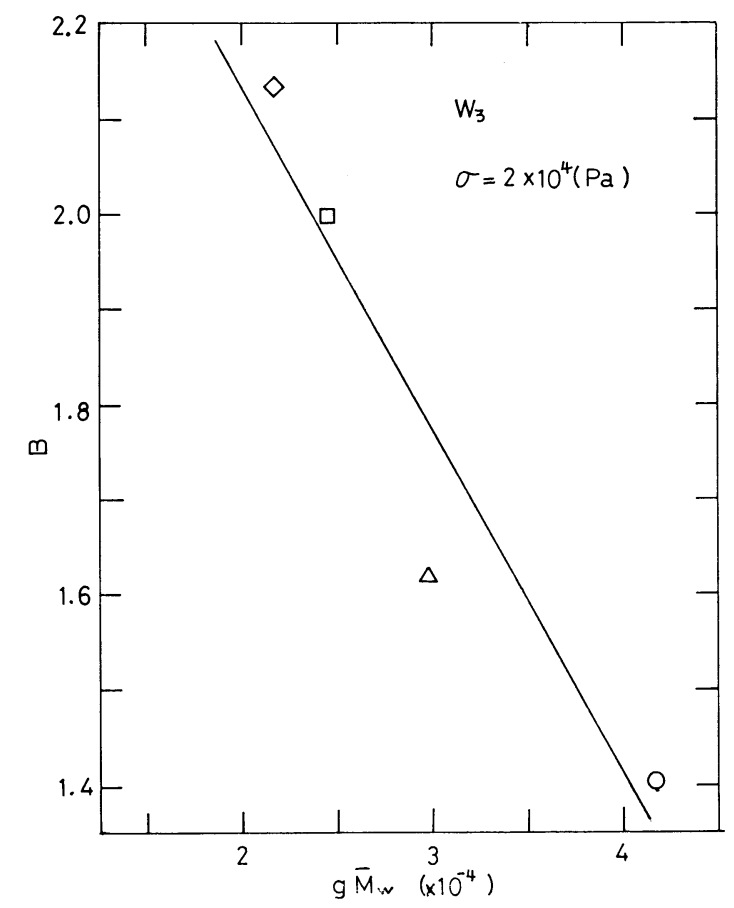

Fig. 8 Die swell plotted against modified molecular weight : shear stress at the wall $=2 \times 10^{4}(\mathrm{~Pa})$.

分岐よりダイスウェルへの影響が大で， $\bar{M}_{w}$ の増大とともにダイ スウェルは増大する結果を示している.

今，パラメーター $g \bar{M}_{w}$ の值が隇少する場合を考えると次の三

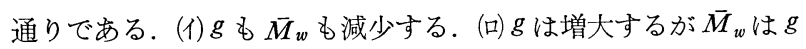
の増大に比し極端に減少する。（价 $\bar{M}_{w}$ は增大するが $g$ は $\bar{M}_{w}$ の 増大に比し極端に減少する。 Ram の報告 ( $g$ の減少とともにダ イスウェルは增大する）を採ると, Fig. 8 の結果に合致するのは 上記(1)，(介)の場合である. 六代の報告（ $\bar{M}_{w}$ の増大ととるにダイ スウェルは増大する）を採ると, Fig. 8 の結果に合致するのは(〉) の場合である. Ram, 六代いずれの報告を採っても Fig. 8 の結 果と合致するのは $g$ の減少する場合である.よって, Fig. 8 は分 岐が大なほどダイスウェルは増大することを示す．これは Wild らの報告, すなわち分岐の增大とともに弾性は增大するという結 果を支持する.

さて, 低密度ポリェチレンの場合, 分岐がダイスウェルに影響 することを述べたが，より重要なことは Fig. 6 に示されたよ5 にダイスウェルがワイセンベルグ数によって規定されたという事 実である. 理論上, ダイスウェルはワイセンベルグ数の関数とさ れている(4),6). 典型的分岐高分子である低密度ポリエチレンもポ リスチレンやポリプロピレンと)と同様にその理論が適用された. これはダイスウェルを単に予測するだけなら分子構造の検討が重 要でないことを意味する. ただし，Fig. 6で高いワイセンベルグ 数ほど実測值と理論值の合致がよくないのは $\mathrm{N}_{1}$ と $\sigma$ との直線性 が高いせん断領域で変化するためと思われる ${ }^{6), 24)}$.

\section{$4 \cdot 2$ せん断履歴の影響}

Rudin ${ }^{25)}$ は塩化ビニルのダイスウェルに試料調整法が影響する ことを示し, ポリスチレン99のダイスウェルにはせん断履歴の影 響が少ないと報告した．また，架橋アセタールを用いたPrichard 26)や低密度ポリエチレンを用いた Howard ら 27 の研究は, せん断
履歴記憶効果として藤木, 六代の総説 ${ }^{28}$ とくわしい. ポリスチレ ンの場合を除いて，いずれもせん断履歷の影響が認められた。

しかし，本報での段階的縮小流の場合，Fig. 7亿みられたよ5 に低密度ポリェチレンのダイスウェルはダイ上流のせん断履歴よ りは出口のダイ寸法に支配され，これは筆者らが高密度ポリエチ レンですでに得た結果 ${ }^{10)}$ と同じであった．前報10)では緩和時間と 滞留時間の比較によりせん断履歴の影響のない現象を説明したが， 本報でも同じ説明が適用可能であった。すなおち，せん断速度が $10 \mathrm{sec}^{-1}$ の時, 緩和時間は約 0.21 秒で, 下部ダイ内滞留時間は 1.24秒であった.

また, $\mathrm{Han}^{7}$ や Bankar $5^{8)}$ (縮小型ダイの出口圧やダイスウェ ルへの流入角の影響を検討し, 流入角には臨界角度があり, それ 以上ではダイスウェルには顕著な影響を示さないと報告している. そこで, 段階的縮小型ダイの場合にも流入角の問題を導入し検討 する必要があろう。

さて, 藤木らのせん断履歴記憶効果は溶媒処理括よび熱処理で 復元（処女試料の状態まで緩和）する. 復元時間は保持温度, メ ルトインデックスに依存する。六代の報告 ${ }^{29}$ （図 5, 図6）から 判断して，リザーバー中で 6 分間予熱中に，それ以前の履歴はほ ぼ復元していると考えられ，ダイ内流動時のせん断履歴の影響だ けをみたことになると思われる。

\section{5. 結 論}

低密度ポリエチレンのダイスウェルは分岐の増加とともに増大 した．段階的縮小型ダイの場合，ダイスウェルは出口ダイの寸法 に規定され，上流に扣けるせん断履歴の影響はなかった。また， 分岐高分子の場合も直鎖高分子と同じくダイスウェルはワイセン ベルグ数に支配された.

〔謝辞〕本研究に協力された井上みよ子技官に謝意を表します。

\section{文献}

1) Horsfall, F., Polymer, 14, 262 (1973).

2) Tanner, R.I., J. Non-Newtonian Fluid Mechanics, 6, 289 (1980).

3) Batchelor, J., J.P. Berry, and F. Horsfall, Polymer, 14, 297 (1973).

4) Reddy, K.R., and R.I. Tanner, J. Rheol., 22, 661(1978).

5) Racin, R., and D.C. Bogue, J. Rheol., 23, 263 (1979).

6) Huang, D.C., and J.L. White, Polym. Eng. Sci., 19, 609 (1979).

7) Han, C.D., J. Appl. Polym. Sci., 17, 1403 (1973).

8) Bankar, V.G., and T.H. Forsyth, SPE ANTEC paper, 19, 281 (1973).

9) Chee, K.K., Y.H. Yap, and A. Rudin, J. Appl. Polym. Sci., 20, 1313 (1976).

10) Suto, S., and T. Fujimura, J. Appl. Polym. Sci., 25, 1509 (1980).

11）須藤新一, 藤村敏一, 山口和則, 高分子論文集, $\mathbf{3 6}, 429$ (1979).

12) Graessley, W.W., and J.S. Prentice, J. Polym. Sci., A-2, 6, 1887 (1968). 
14) Mendelson, R.A., W.A. Bowles, and F.L. Finger, J. Polym. Sci., A-2, 8, 127 (1970).

15) Miltz, J., and A. Ram, Polym. Eng. Sci., 13, 273 (1973).

16）熊崎昌治，志賀 勇，橋本 淳，日本レオロジー学会誌, 3, 97 (1975).

17）六代 稔, 日本レオロジー学会誌, 8, 161 (1980).

18) Mendelson, R.A., and F.L. Finger, J. Appl. Polym. Sci., 17, 797 (1973).

19) Wild, L., R. Ranganath, and D.C. Knobeloch, Polym. Eng. Sci., 16, 811 (1976).

20) Rokudai, M., J. Appl. Polym. Sci., 26, 1427 (1981).

21) Zimm, B.H., and W.H. Stockmayer, J. Chem. Phys.,
17, 1301 (1949).

22) Bueche, F.J., J. Chem. Phys., 20, 1959 (1952).

23) Ram, A., Polym. Eng. Sci., 17, 793 (1977).

24) Han, C.D., Trans. Soc. Rheol., 18, 163 (1974).

25) Rudin, A., SPE-J., 26(2), 57 (1970).

26) Prichard, J.H., and K.F. Wissbrum, J. Appl. Polym. Sci., 13, 233 (1963).

27) Howard, J.B., and H.M. Gilroy, $S P E-J .$, 24(1), 68 (1968).

28）藤木時男, 六代 稔, 日本レオロジー学会誌, 6, 146 (1978).

29) Rokudai, M., J• Appl. Polym. Sci., 23, 463 (1979). 